\title{
How physics instruction impacts students' beliefs about learning physics: A meta-analysis of 24 studies
}

\author{
Adrian Madsen, ${ }^{1}$ Sarah B. McKagan, ${ }^{1}$ and Eleanor C. Sayre ${ }^{2}$ \\ ${ }^{1}$ American Association of Physics Teachers, College Park, Maryland 20740, USA \\ ${ }^{2}$ Kansas State University, Manhattan, Kansas 66506, USA
}

(Received 21 March 2014; revised manuscript received 3 March 2015; published 2 June 2015)

\begin{abstract}
In this meta-analysis, we synthesize the results of 24 studies using the Colorado Learning Attitudes about Science Survey (CLASS) and the Maryland Physics Expectations Survey (MPEX) to answer several questions: (1) How does physics instruction impact students' beliefs? (2) When do physics majors develop expert-like beliefs? and (3) How do students' beliefs impact their learning of physics? We report that in typical physics classes, students' beliefs deteriorate or at best stay the same. There are a few types of interventions, including an explicit focus on model-building and (or) developing expertlike beliefs that lead to significant improvements in beliefs. Further, small courses and those for elementary education and nonscience majors also result in improved beliefs. However, because the available data oversamples certain types of classes, it is unclear whether these improvements are actually due to the interventions, or due to the small class size, or student populations typical of the kinds of classes in which these interventions are most often used. Physics majors tend to enter their undergraduate education with more expertlike beliefs than nonmajors and these beliefs remain relatively stable throughout their undergraduate careers. Thus, typical physics courses appear to be selecting students who already have strong beliefs, rather than supporting students in developing strong beliefs. There is a small correlation between students' incoming beliefs about physics and their gains on conceptual mechanics surveys. This suggests that students with more expertlike incoming beliefs may learn more in their physics courses, but this finding should be further explored and replicated. Some unanswered questions remain. To answer these questions, we advocate several specific types of future studies: measuring students' beliefs in courses with a wider range of class sizes, student populations, and teaching methods, especially large classes with very innovative pedagogy and small classes with more typical pedagogy; analysis of the relationship between students' beliefs and conceptual understanding including a wide variety of variables that might influence each; and analysis of large data sets from a variety of classes that track individual students rather than averaging over classes.
\end{abstract}

DOI: 10.1103/PhysRevSTPER.11.010115

PACS numbers: 01.40.-d

\section{INTRODUCTION AND SUMMARY OF FINDINGS}

Physics faculty care about their students learning physics content. In addition, they usually hope that their students will learn some deeper lessons about thinking critically and scientifically. They hope that as a result of taking a physics class students will come to appreciate physics as a coherent and logical method of understanding the world, and recognize that they can use reason and experimentation to figure things out about the world. While it is relatively straightforward to measure students' understanding of physics content, it is much more difficult to measure how much they think like a physicist and what they believe about the nature of physics and learning physics. Physics education researchers have created several surveys to measure students' beliefs about physics [1-5]. Two

Published by the American Physical Society under the terms of the Creative Commons Attribution 3.0 License. Further distribution of this work must maintain attribution to the author(s) and the published article's title, journal citation, and DOI. commonly used surveys are the Maryland Physics Expectations Survey (MPEX) [1] and the Colorado Learning Attitudes about Science Survey (CLASS) [2]. These surveys are not about whether students like physics, but about how students perceive the discipline of physics or their particular physics course. These surveys ask students to rank statements using a 5-point Likert scale from strongly agree to strongly disagree. The most common way to score these surveys is to collapse students' responses into a binary depending on whether they are the same as an expert physicist would give (we will call this "percent expertlike response", in the literature it is commonly called "percent favorable response"). They are usually given as a pre- and post-test to measure the "shift," or change in students' beliefs over the course of a semester. Work has also been done using these surveys to study how students' beliefs change over the course of their undergraduate careers.

These surveys have been given to thousands of students at a variety of institutions across the United States. A rich set of results has emerged on how the scores vary by 
teaching method, over time, and correlate with other measures [such as the Force Concept Inventory (FCI) [6] and the Force and Motion Conceptual Evaluation (FMCE) [7]]. In this paper, we bring together these results to answer several questions:

(1) How does physics instruction impact students' beliefs?

(2) When do physics majors develop expertlike beliefs?

(3) How do students' beliefs impact their learning of physics?

\section{HOW CAN WE ASSESS STUDENTS' BELIEFS ABOUT LEARNING PHYSICS?}

To answer our questions about how physics instruction impacts students' beliefs about learning physics, we examine the set of published results on the CLASS and MPEX. These surveys measure students' self-reported beliefs about physics and how closely these beliefs about physics align with experts' beliefs. The surveys ask students questions about how they learn physics, how physics is related to their everyday lives, and how they think about the discipline of physics. Example questions are given in Table I. A list of the categories of questions for each test is available in the Appendix. Because this is self-reported data, we cannot know how well the beliefs students report on the CLASS or MPEX correspond to the ways they actually think about physics. For example, a student might say and really believe, "When I am solving a physics problem, I try to decide what would be a reasonable value for the answer," but not do that in real life.

TABLE I. Example items from the CLASS and MPEX. Statements that experts agree with are indicated in bold.

\begin{tabular}{|c|c|}
\hline CLASS & MPEX \\
\hline $\begin{array}{l}\text { I study physics to learn } \\
\text { knowledge that will be } \\
\text { useful in my life outside } \\
\text { of school. }\end{array}$ & $\begin{array}{l}\text { - Learning physics helps me } \\
\text { understand situations } \\
\text { in my everyday life. }\end{array}$ \\
\hline $\begin{array}{l}\text { A significant problem in } \\
\text { learning physics is being } \\
\text { able to memorize all the } \\
\text { information I need to know. }\end{array}$ & $\begin{array}{l}\text { A significant problem } \\
\text { in this course is being } \\
\text { able to memorize all the } \\
\text { information } \\
\text { I need to know. }\end{array}$ \\
\hline $\begin{array}{l}\text { Knowledge in physics } \\
\text { consists of many pieces } \\
\text { of information each of } \\
\text { which applies primarily } \\
\text { to a specific situation. }\end{array}$ & $\begin{array}{l}\text { Knowledge in physics } \\
\text { consists of many } \\
\text { disconnected topics. }\end{array}$ \\
\hline $\begin{array}{l}\text { If I get stuck on a physics } \\
\text { problem on my first try, } \\
\text { I usually try to figure } \\
\text { out a different way } \\
\text { that works. }\end{array}$ & $\begin{array}{l}\text { - In doing a physics problem, } \\
\text { if my calculation gives a } \\
\text { result that differs } \\
\text { significantly from what } \\
\text { I expect, I'd have to trust } \\
\text { the calculation. }\end{array}$ \\
\hline
\end{tabular}

We picked the CLASS and MPEX because they are the most commonly used surveys of beliefs about physics. Further, the questions on these two tests overlap to some degree and they are designed to measure a similar aspect of students' beliefs, so it seems reasonable to look at the results of these tests together. Table XI in the Appendix describes several important characteristics of each survey.

\section{HOW DOES PHYSICS INSTRUCTION IMPACT STUDENTS' BELIEFS?}

To determine how physics instruction impacts students' beliefs, we conducted a literature review to find relevant studies. We identified 24 studies published in Physical Review Special Topics-Physics Education Research, American Journal of Physics, and the Physics Education Research Conference Proceedings that reported CLASS or MPEX results for undergraduate physics classes in the United States and Canada. Because of the variability of the education systems in other countries, we did not include studies from outside the United States and Canada. For those interested in these international studies, see Refs. [8-11]. Where there was insufficient information, such as missing information about error or average pre- and post-test scores, we contacted the authors for clarification and (or) additional data. There were three studies where the authors did not write back or the error information was no longer available. There were an additional three studies where the authors did not calculate error.

We chose to look at the shifts in overall average percent expertlike responses (shifts) from pre- to post-test on the CLASS or MPEX. This shift is found by

(i) determining, for each student, the percentage of the responses that are in agreement with the expert answer on the pre- and post-test,

(ii) averaging these individual scores to find the average percent expertlike on the pre- and post-test for the entire class, and

(iii) subtracting the pretest average percent expertlike from the post-test average percent expertlike.

This metric tells us how students' expertlike beliefs about physics changed from the start to the end of their physics course. Ideally, we would like this value to increase as a result of physics instruction. We chose this metric instead of average percent unfavorable scores because it is more commonly reported in the literature. Of the 24 studies we examined, only seven reported the shift in percent unfavorable scores [1,4,12-15]. Further, the shifts in favorable beliefs (expertlike beliefs) are almost always in the opposite direction to the shifts in unfavorable beliefs (novicelike beliefs), as expected, therefore, looking only at favorable shifts gives us similar information as looking at unfavorable beliefs. Of the seven studies that reported unfavorable beliefs, only one course [14] reported positive shifts in both the favorable and unfavorable scores (this can happen when students shift from neutral answer choices on 


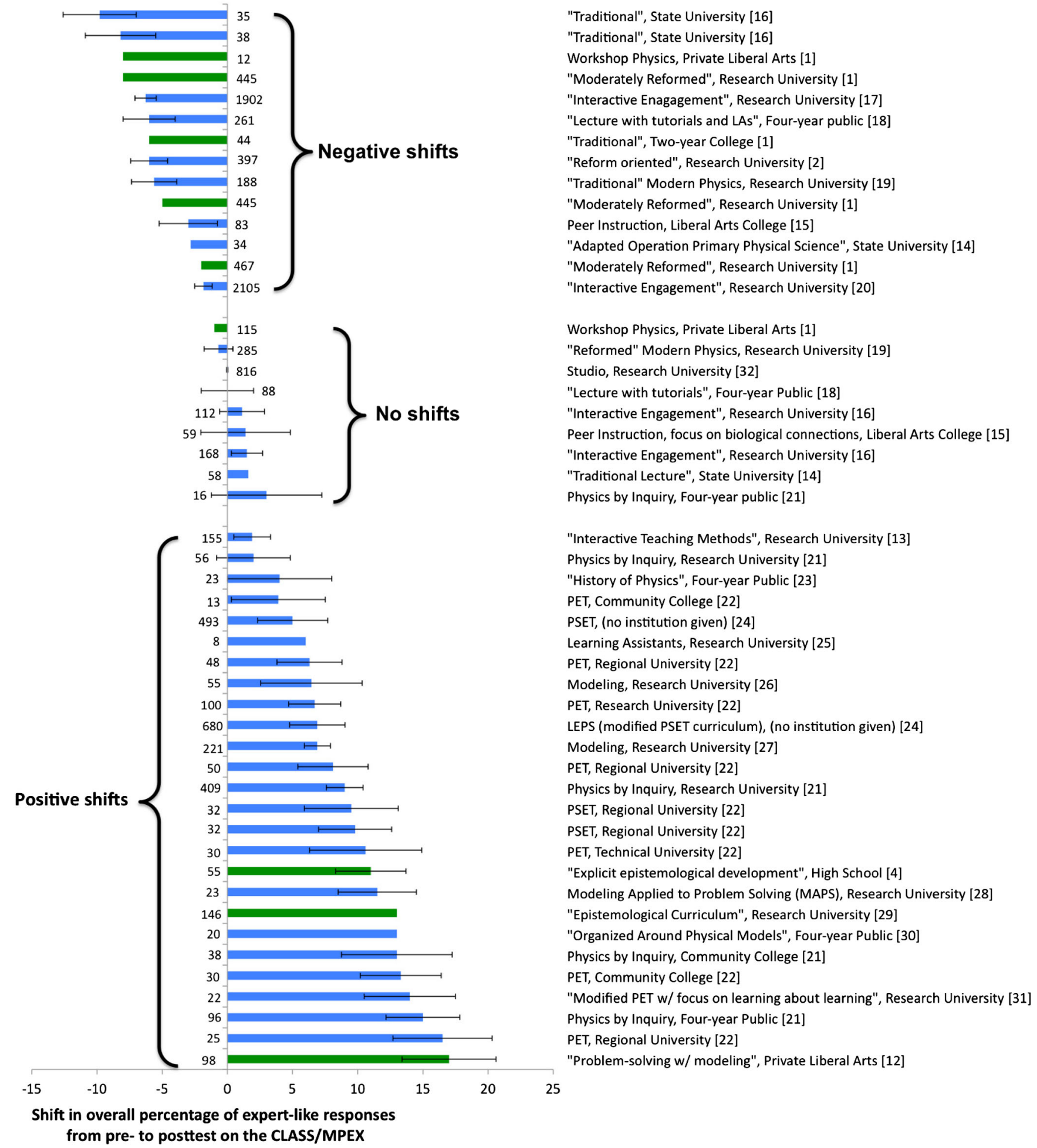

FIG. 1. Shifts in percent expertlike on CLASS or MPEX scores from pre- to post-test based on direction of the shift. Numbers next to bars indicate the number of students in the study. Error bars represent standard error. Error bars were not available for all studies. Green bars indicate that the MPEX or MPEX-II was used. In all other cases the CLASS was used. PET = Physics of Everyday Thinking curriculum, PSET $=$ Physical Science of Everyday Thinking curriculum. 
the pretest to positive and negative answer choices on the post-test).

Studies that used matched data, those where shifts are calculated using the same individual students for both the pre- and post-test, as opposed to using the class average pretest and post-test scores, most accurately represent the change in students' beliefs. This is because shifts calculated using unmatched data are more susceptible to selection effects, as students with less expertlike beliefs are most likely to drop the course or not fill out the survey at the end of the semester. Of the 24 studies included in our analysis, 12 reported using matched data. Four studies reported using matched conceptual assessment data, but did not report whether their CLASS or MPEX data were matched. Six studies did not report whether their data were matched or not, though five of these six studies gave one " $n$ " value for the number of students in their data set. One of these six studies reported only the number of students enrolled in the course. Based on this information, we can assume that most of the studies included in our analysis use matched data, but we cannot know for sure.

The questions on both the MPEX and CLASS can be clustered into different categories. We chose to focus on the overall shift (for all categories) instead of looking at individual categories because this is what is consistently reported in almost all studies. Further, the categories on the MPEX and CLASS are different, making comparisons between the two difficult.

Figure 1 shows the shifts grouped by their direction (negative [1,2,14-20], positive [4,12,13,21-31], or no shift $[1,14-16,18,19,21,32])$. The direction of the shift is that which was reported in the study. We report the number of students for each study as given in the paper. Where there was more than one course at the same institution taught using the same teaching method, we used a weighted average to combine the results. We were not able to obtain error for several studies, so we were not able to determine effect size. Our meta-analysis includes results from both the CLASS and MPEX. In Fig. 1, we see that the shifts for MPEX data are comparable to the shifts for CLASS data for similar types of courses and institutions, so we believe that further normalization of the results from these different tests is not necessary. There is one positive shift bar in Fig. 1, "Physics by Inquiry, Research University [21]," where the error bars cross zero. In this study, the distributions of CLASS scores deviated from the normal distribution, so statistical significance of the gains was determined using the nonparametric Wilcoxon signed-rank test. When using the Wilcoxon signed-rank test, error bars can overlap zero, and the result can still be statistically significant. See Ref. [33] for a discussion of this test and an illustration of error bars that overlap zero but are still significant at the 0.04 level.

Using Fig. 1, we looked for similarities between the courses in each shift category. We noticed many factors that may have contributed to the differences in the shift categories including teaching method, class size, population, and pretest scores. Many of these factors are confounded; for example, most of the classes with large positive shifts are those using curricula with a focus on model building, which are implemented in small classes and often offered to future elementary teachers. Courses with negative shifts tend to be calculus based with large enrollments and taught in a reformed or traditional manner.

We conducted a three-way type I ANOVA to test the influence of teaching method, class size, and student population on the CLASS and MPEX shifts. We chose a type I ANOVA because there is an inherent ordering of these factors according to what is more educationally easy to change. Student population is ordered first in our analysis as this is the least easy for a faculty member to change. Next, class size is widely determined outside of an instructor's purview. Third in order is teaching method, as this is something a faculty member could indeed have influence over.

We found no significant three-way interaction or twoway interactions in our analysis. We tested the main effects of each factor. All three factors were found to be significant at the $p<0.01$ level (Table II). We used a Tukey HSD post hoc test to determine which levels of the factors were significantly different. These differences will be discussed in the following sections. However, the published data set of CLASS and MPEX results is deeply unbalanced, meaning there are many combinations of teaching method, class size, and student population that have no data or very few data points in them (see Tables III-V). This means that we are not fairly testing all combinations of factors and

TABLE II. Results of three-way type 1 ANOVA comparing the affect of student population, class size, and teaching method on shifts on the CLASS and MPEX. All three factors were significant at the $p<0.01$ level. The three- and two-way interactions were not significant. "df" = degrees of freedom.

\begin{tabular}{lcrc}
\hline \hline Factor & df & $F$ & $p$ \\
\hline Student population & 3 & 15.8 & $7.9 \times 10^{-7}$ \\
Class size & 2 & 5.4 & 0.009 \\
Teaching method & 3 & 27.4 & $1.3 \times 10^{-9}$ \\
\hline \hline
\end{tabular}

TABLE III. Number of courses for each combination of student population and class size, “..." indicates no courses have a given combination.

\begin{tabular}{cccccc}
\hline \hline & \multicolumn{4}{c}{ Student population } \\
\cline { 2 - 5 } & & $\begin{array}{c}\text { Algebra- Calculus- } \\
\text { based }\end{array}$ & $\begin{array}{c}\text { Elementary and } \\
\text { based }\end{array}$ & $\begin{array}{c}\text { Upper } \\
\text { Nonscientists }\end{array}$ & \begin{tabular}{c} 
level \\
\hline Class
\end{tabular} Small \\
size Medium & 1 & 9 & 16 & 2 \\
Large & 1 & 10 & 7 & 3 \\
\hline \hline
\end{tabular}


TABLE IV. Number of courses for each combination of teaching method and student population, “..." indicates no courses have a given combination.

\begin{tabular}{lccccc}
\hline \hline & & \multicolumn{3}{c}{ Teaching method } \\
\cline { 3 - 6 } & & $\begin{array}{c}\text { Focus on } \\
\text { modeling }\end{array}$ & $\begin{array}{c}\text { Explicit focus } \\
\text { on developing } \\
\text { beliefs }\end{array}$ & $\begin{array}{c}\text { Some focus } \\
\text { on developing } \\
\text { beliefs }\end{array}$ & $\begin{array}{c}\text { Ordinary courses } \\
\text { (reformed and } \\
\text { traditional) }\end{array}$ \\
\hline Student population & Algebra based & $\ldots$ & 1 & $\ldots$ & 1 \\
& Calculus based & 6 & $\ldots$ & 2 & 16 \\
& Upper level & $\ldots$ & 1 & 2 & 4 \\
\hline \hline
\end{tabular}

TABLE V. Number of courses for each combination of class size and teaching method, "..." indicates no courses have a given combination.

\begin{tabular}{clrcc}
\hline \hline & \multicolumn{3}{c}{ Class size } \\
\cline { 3 - 5 } & Small & Medium & Large \\
\hline $\begin{array}{c}\text { Teaching } \\
\text { method }\end{array}$ & $\begin{array}{c}\text { Focus on modeling } \\
\text { Explicit focus on } \\
\text { developing beliefs } \\
\text { Some focus on } \\
\begin{array}{c}\text { developing beliefs } \\
\text { Ordinary courses } \\
\text { (reformed and traditional) }\end{array}\end{array}$ & 18 & 5 & $\ldots$ \\
\hline \hline
\end{tabular}

cannot accurately determine the influence of factors associated with the sparse or missing data. Because the data set is unbalanced and there are many cells with zero data (Tables III-V), it is important to avoid overinterpreting these results. Since we are drawing data from the published record, the unbalanced nature of the data is unavoidable.

Below we describe how teaching method, class size, student population, and pretest scores may influence shifts on the CLASS and MPEX.

\section{A. Impact of teaching method on students' beliefs}

The literature on the CLASS and MPEX is full of claims focusing on how different teaching methods or curricula lead to differing shifts in CLASS or MPEX scores. After one semester of traditional or research-based reformed physics instruction, it is common to report negative shifts on these surveys $[1,2]$. There are many other studies that find positive shifts in beliefs and contain claims about the teaching method that lead to these shifts (Table VI). There is very little mention of other factors besides teaching method or curriculum that may influence CLASS and MPEX shifts. In this section, we test some of these claims by aggregating the data for different types of teaching methods and comparing our results to claims in the literature.

Figure 2 shows shifts grouped by teaching method. Three studies reported on courses with an explicit focus on developing students' expertlike beliefs about physics and all resulted in positive shifts $[4,23,29]$. Examples of strategies include labs, which helped students see that physics involves refining and reconciling intuitive ideas [4], activities where students reflected on their learning process, explicit epistemological framing of the course and use of associated vocabulary [4], modified Peer Instruction with discussions of intuitive answers to questions [4], "epistemologized" tutorials emphasizing the reconciliation of intuitive thinking and formal scientific thinking [29], and focus on the development of scientific ideas throughout history [23].

There were three studies where the instructors paid "some" attention to developing expertlike beliefs. These studies showed a small negative shift, no shift, or a small positive shift in beliefs. Examples of strategies included developing reasoning skills such as making inferences from

TABLE VI. Teaching methods associated with positive shifts on the CLASS or MPEX as documented in the literature.

Courses that engage students in authentic scientific practices like building models of the physical world [26,27].

Course for life science majors organized around rich biological models and taught using interactive engagement techniques [15].

Explicit focus on epistemological development [4].

Epistemological curriculum for life-science majors [29].

Teaching physics in the context of its historical development [23].

Physics and Everyday Thinking curriculum [22] with a special focus on learning about learning [31].

Physics by Inquiry curriculum [21].

No explicit instructional intervention [12].

Modern physics course with reasoning development, model building, and connections to real world applications [19].

Serving as a Learning Assistant [25]. 


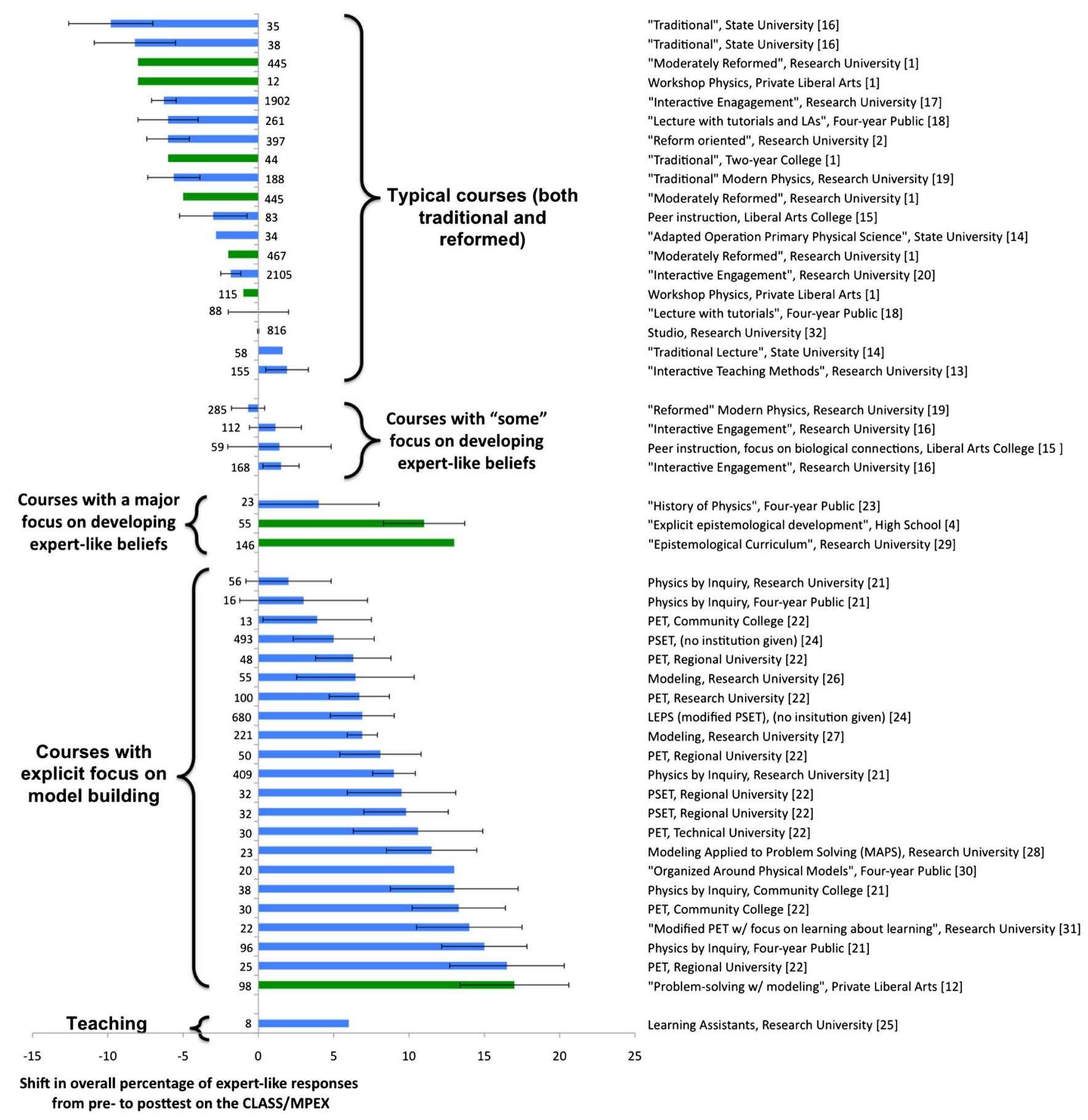

FIG. 2. Shifts in percent expertlike on CLASS or MPEX by teaching method. Courses taught with traditional and reformed methods showed varying levels of positive and negative shifts. Courses that paid some attention to developing beliefs had no shift. Those that put a major focus on developing positive beliefs had positive shifts. Courses that explicitly focused on model building also had positive shifts. One small study of learning assistants found that these students also had a positive shift in beliefs. Classification of courses was determined by authors based on description of course provided in paper. PET = Physics of Everyday Thinking curriculum, PSET = Physical Science of Everyday Thinking curriculum.

observations and understanding why we believe scientific ideas [19] and helping students make personally meaningful connections to the content to increase interest [15]. (Another study cited their attention to student beliefs but did not explain how they did so [16]).
Several studies reported on courses that focused explicitly on developing models of the physical world. Commonly used curricula include Physics by Inquiry [34], Modeling Instruction [26], and Physics and Everyday Thinking [35] (also Physical Science and 
Everyday Thinking). Almost all of the courses taught with these curricula resulted in large positive shifts in CLASS and MPEX scores. A few courses using these curricula had small positive shifts or no shift, but no courses had negative shifts. These curricula are structured so that students work in small groups to perform experiments and gather evidence in order to build models of the physical world. They also participate in small group and whole classroom discourse to understand, validate, and refine these models, mirroring the way scientists create new knowledge. These curricula differ in the amount that they explicitly focus on learning about learning and all but one of the courses using these curricula show positive shifts in students' beliefs. There are other studies that report large positive shifts that also focus on models of the physical world, but do not use the curricula listed above $[12,28,30]$.

Additional studies described traditional or reformed courses where teaching methods designed to improve beliefs or explicitly develop models of the physical world were not used $[1,2,4,12-15,19,20]$ (we refer to these as ordinary teaching methods). These courses may have included some elements of model building, but this was not the main focus of the course. These courses were associated with positive, zero, or negative shifts in beliefs.

To test the effect of these teaching methods on shifts in beliefs, we conducted a follow-up one-way ANOVA with teaching method as the independent variable and shift as the dependent variable (details of initial ANOVA discussed in the introduction). We found a significant difference in shift in CLASS and MPEX score based on teaching method $[F(3,52)=698.2, p<0.0001]$. Using a Tukey HSD post hoc pairwise comparison test, we measured the differences between these four methods (Table VII). Modeling and explicit focus are not significantly different from each other $(p=0.99)$, and they are both better than teaching methods with "some" focus (modeling $p<0.001$, explicit focus $p=0.08$ ), which is in turn better than ordinary teaching methods (modeling $p<0.0001$, explicit $p<0.0001$, some focus $p=0.08$ ).

Overall, these studies suggest that courses that focus explicitly on developing students' beliefs about physics and those that are explicitly focused on building models of the physical world lead to the greatest positive shifts in student beliefs. These courses help students reflect on their learning, engage with their intuitive ideas and formal scientific thinking, and understand how scientific knowledge is created. Courses with some focus on developing beliefs have marginally greater shifts than ordinary courses, so even paying some attention to developing beliefs is of benefit to students.

Traditional courses and reformed courses where students have large gains on conceptual assessment have a range of shifts, but most result in large negative shifts in beliefs. Strong conceptual understanding does not automatically result in improved beliefs about physics. Attention to the process of learning science is likely necessary to improve beliefs, but not sufficient. Below we explore other factors in addition to teaching method that may be influencing students' shifts in beliefs.

\section{B. Impact of class size on students' beliefs}

In Fig. 2, we notice that many of the courses with positive shifts also tend to be small classes. It could be that positive shifts in beliefs are directly related to class size, so this factor should be further investigated. Perhaps the small class environment allows different kinds of interaction and discourse that help develop expertlike beliefs or the kinds of teaching methods that help students develop expertlike beliefs (Modeling, Problem-Based Inquiry, Physical Science and Everyday Thinking, etc.) also happen to be those that work with a small class size.

To investigate the effect of class size, we plotted class size versus shift from pre- to post-test for small, medium, and large class sizes (Fig. 3). We chose the cutoffs for medium and large classes using our intuition of the dynamics of different sized classes and also looked for natural cut points in the data. Small classes were those with 12 to 38 students, medium classes enrolled 42 to 100 students, and large classes enrolled 115 to 448 students. We found that the average shift for small classes (5.4) was larger than that of medium classes (.94), and large classes (-1.7).

The results of the three-way ANOVA (discussed in the introduction) revealed a significant effect of class size on

TABLE VII. Results of Tukey-HSD post hoc pairwise contrasts comparing shifts for different teaching methods.

\begin{tabular}{|c|c|c|c|c|}
\hline & \multicolumn{4}{|c|}{ Teaching method and shifts in CLASS and MPEX scores } \\
\hline & $\begin{array}{c}\text { Focus on modeling } \\
\text { shift: } 9.3 \%\end{array}$ & $\begin{array}{c}\text { Explicitly focus on } \\
\text { developing beliefs } \\
\text { shift: } 8.5 \%\end{array}$ & $\begin{array}{l}\text { Some focus on } \\
\text { developing beliefs } \\
\text { shift: } 0.7 \%\end{array}$ & $\begin{array}{c}\text { Ordinary methods } \\
\text { shift: }-3.7 \%\end{array}$ \\
\hline Focus on modeling shift: $9.3 \%$ & $\ldots$ & $p=0.99$ & $p=0.001$ & $p=0.0001$ \\
\hline $\begin{array}{l}\text { Explicitly focus on developing } \\
\text { beliefs shift: } 8.5 \%\end{array}$ & $\cdots$ & $\cdots$ & $p=0.08$ & $p=0.0001$ \\
\hline $\begin{array}{l}\text { Some focus on developing } \\
\text { beliefs shift: } 0.7 \%\end{array}$ & $\cdots$ & $\cdots$ & $\cdots$ & $p=0.08$ \\
\hline Ordinary methods shift: $-3.7 \%$ & $\ldots$ & $\cdots$ & $\ldots$ & $\cdots$ \\
\hline
\end{tabular}




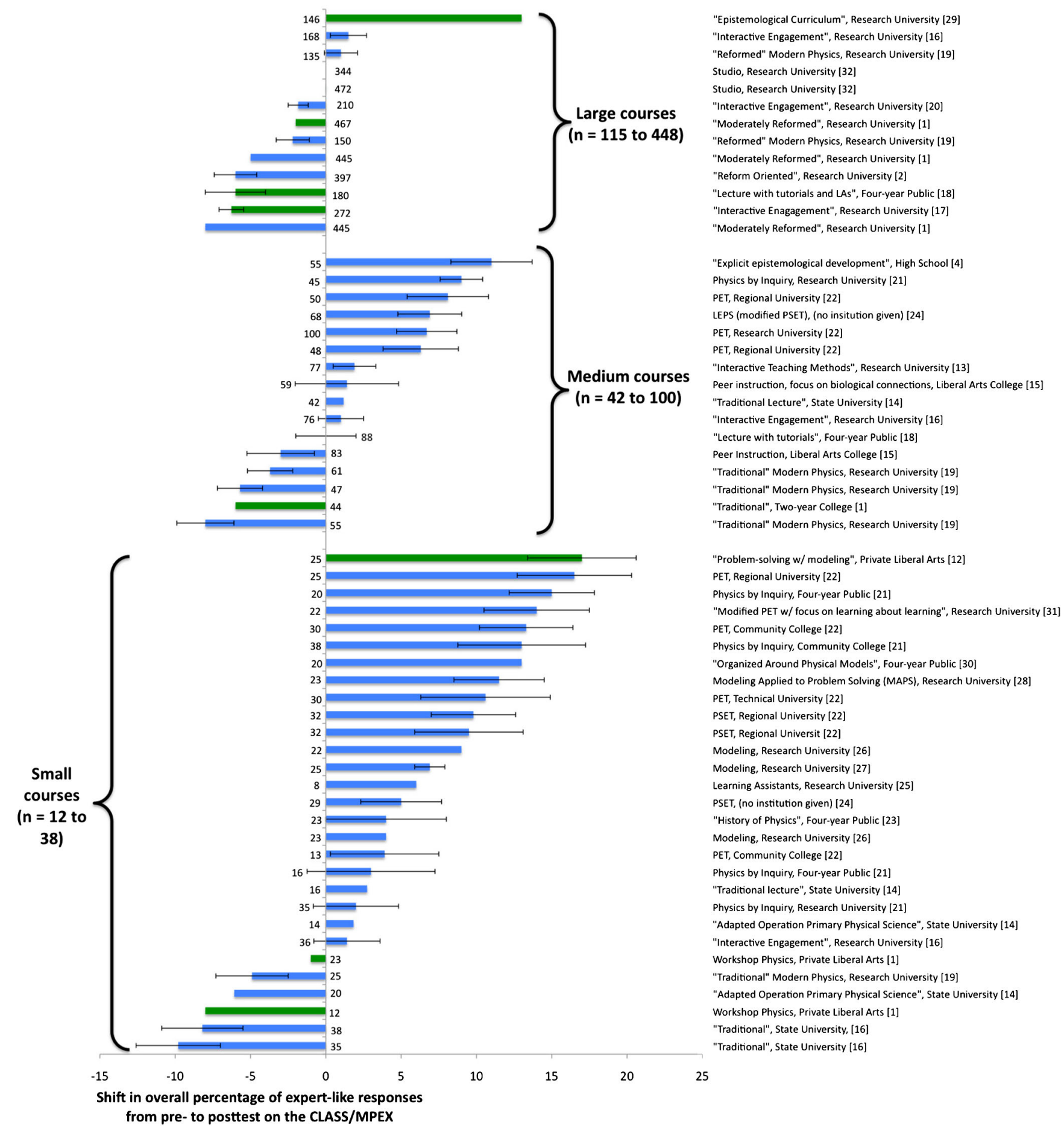

FIG. 3. Shifts in CLASS or MPEX by class size. The average shift for small classes is positive and for large classes is negative. There is a bar for each unique course at a given institution taught with a given teaching method. In the case of the same course taught for multiple semesters, we used a weighted average to combine the results and display as a single bar. The total number of students is used as the class size for large lecture courses where students attended smaller lab or recitation sections. There were several studies where the total number of students and number of course sections were reported. Here we found the average class size by dividing the total number of students by the number of sections.

shifts and no interactions between class size and other factors. We followed up with a one-way ANOVA with class size as the independent variable and shift as the dependent variable. We found a significant main effect for class size
$[F(2,53)=5.4, p=0.007]$. Using a Tukey HSD post hoc pairwise comparison test, we measured the differences between these three class sizes (Table VIII). Small classes had significantly greater shifts in CLASS and MPEX shifts 
TABLE VIII. Results of Tukey-HSD post hoc pairwise contrasts comparing shifts for different class sizes. Small classes have statistically significant greater positive shifts than large classes.

\begin{tabular}{lccc}
\hline \hline & \multicolumn{3}{c}{ Class size and shifts in } \\
& \multicolumn{3}{c}{ CLASS and MPEX scores } \\
\cline { 2 - 4 } & Small & Medium & Large \\
& shift: $5.4 \%$ & shift: $0.9 \%$ & shift: $-1.7 \%$ \\
\hline Small shift: $5.4 \%$ & $\ldots$ & $p=0.11$ & $p=0.008$ \\
Medium shift: $0.9 \%$ & $\ldots$ & $\ldots$ & $p=0.56$ \\
Large shift: $-1.7 \%$ & $\ldots$ & $\ldots$ & $\cdots$ \\
\hline \hline
\end{tabular}

than large classes $(p=0.008)$. Small and medium classes are not significantly different from each other $(p=0.11)$. Medium and large classes are also not significantly different from each other $(p=0.56)$.

\section{Impact of student population on beliefs}

In addition to class size being an important factor, the student population in each course might also be important. For example, many of the courses with large positive shifts on the CLASS and MPEX are courses taught to elementary education majors and many with large negative shifts are calculus-based physics courses. It may be that certain student populations have larger shifts in beliefs about physics than others. We plotted the student population types versus shift on the CLASS and MPEX (Fig. 4). We find that with almost every population type, there is a range of shifts from positive to negative, with the exception of elementary education majors and nonscience majors, where the majority of the courses show positive shifts.

The results of the three-way ANOVA (discussed in the introduction) revealed a significant effect of student population on shifts and no interactions between student population and other factors. We followed up with a one-way ANOVA with student population as the independent variable and shift as the dependent variable. We found a significant main effect for student population $[F(3,52)=5.8, p=0.002]$. Using a Tukey HSD post hoc pairwise comparison test, we measured the differences between these four student populations (Table IX). Courses for elementary education and nonscience majors have greater shifts than calculus-based courses $(p=0.006)$. Upper-level courses have greater gains than courses for elementary education and nonscience majors $(p=0.007)$. All other combinations of student populations were not significantly different, indicating there are differences in CLASS and MPEX shifts based on student population.

\section{Impact of pretest scores on shifts in students' beliefs}

It is also important to determine if and how pretest scores are related to the shifts. It could be that those who come into the class with more or less expertlike beliefs may make larger shifts in scores, regardless of how the course is taught, how large the enrollment, or the student population enrolled in the course.

We plotted pretest score versus shift for our data set (Figs. 5 and 6). We conducted a one-way ANOVA to test the effect of pretest score on CLASS and MPEX shift. We found a significant main effect $[F(1,48)=731.1$, $p<0.0001]$ of the pretest score. This ANOVA indicates that as CLASS and MPEX pretest scores increase, shifts on CLASS and MPEX decrease, but before drawing conclusions from this analysis, we need to consider underlying factors that may be influencing the relationship between pretest scores and shifts, e.g., differences in shifts and pretest scores by student population or teaching method. To investigate how these additional factors are related to pretest score and shift, we color coded the dots in the scatter plots to correspond to different teaching methods (Fig. 5) and student populations (Fig. 6). Further, we used a two-way type 2 ANOVA to first test the effect of teaching method and pretest score on shifts (We choose a type 2 ANOVA because the order of the factors teaching method and pretest is not inherently meaningful). We found that pretest was marginally significant $[F(1,45)=2.95$, $p=0.09$ ] and teaching method was highly significant $[F(1,45)=36.4, p<0.0001]$. So, teaching method is the strongest predictor of shift, even when we take into account pretest score.

We find a lack of relationship between pretest scores and shifts when teaching method is taken into account, but teaching method cannot influence pretest scores, since the pretest is taken before any substantial teaching takes place. A factor that could influence pretest scores is student population. In this data set, the courses that focus on model building are primarily taught to elementary education majors and nonscience majors while ordinary courses are usually calculus based. We used a two-way type 2 ANOVA to test the effect of student population and pretest score on shifts. We found that pretest was marginally significant $[F(1,45)=3.7, p=0.06]$ and student population was also marginally significant $[F(3,45)=2.7$, $p=0.06]$. In this case, neither pretest score or student population are highly predictive of shifts on the CLASS and MPEX.

Overall, we find that teaching method is the strongest predictor of shifts on the CLASS and MPEX, even when pretest scores are taken into account. Student population and pretest score are marginally predictive of these shifts. These data suggest that teaching method is the most important factor for determining shifts in beliefs about physics, but pretest score and student population may also be important. This analysis would be more powerful if we had a balanced data set (discussed in the Introduction). Further, if we could examine the data by individual student rather than data averaged over the entire class, we could better determine how the characteristics of students influence pretest score. 


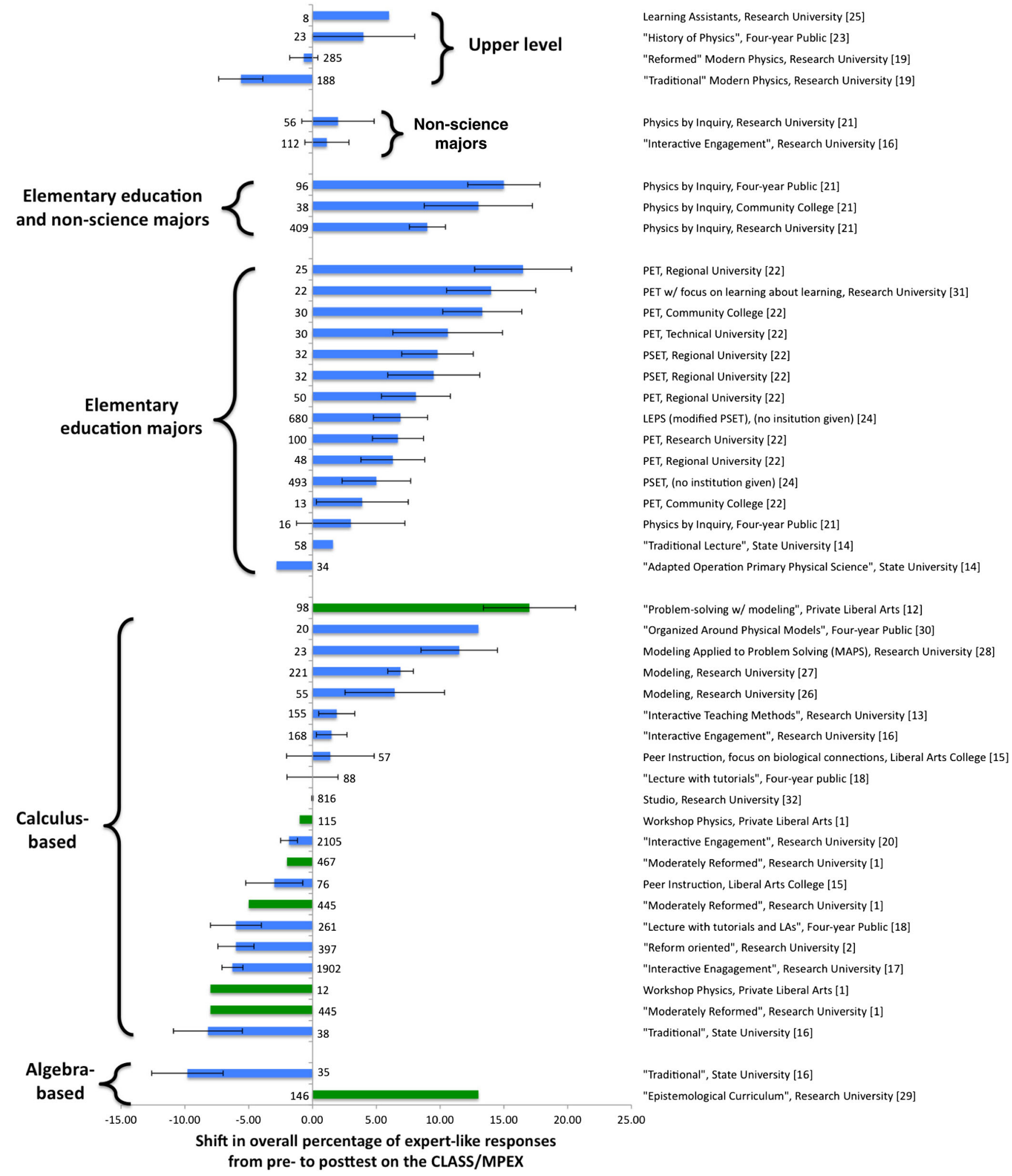

FIG. 4. Shifts in CLASS or MPEX by student population. Nearly all student population categories include courses with both positive and negative shifts on the CLASS and MPEX, with the exception of courses for elementary education majors and courses for both elementary education majors and nonscience majors, where all but one of the shifts are positive. 
TABLE IX. Significant results of statistical comparison between student populations using Tukey HSD post hoc contrasts. Courses for elementary education and nonscience majors have significantly greater shifts than calculus-based or upper-level courses.

\begin{tabular}{|c|c|c|c|c|}
\hline & \multicolumn{4}{|c|}{ Student population and shifts in CLASS and MPEX scores } \\
\hline & $\begin{array}{c}\text { Elementary education } \\
\text { and nonscience majors } \\
\text { shift: } 6.7 \%\end{array}$ & $\begin{array}{l}\text { Calculus-based } \\
\text { shift: } 0.2 \%\end{array}$ & $\begin{array}{l}\text { Algebra-based } \\
\text { shift: } 1.6 \%\end{array}$ & $\begin{array}{l}\text { Upper-level } \\
\text { shift: }-2.8 \%\end{array}$ \\
\hline $\begin{array}{l}\text { Elementary education and nonscience } \\
\text { majors shift: } 6.7 \%\end{array}$ & $\cdots$ & $p=0.006$ & $p=0.71$ & $p=0.007$ \\
\hline Calculus-based shift: $0.2 \%$ & $\cdots$ & $\cdots$ & $p=0.99$ & $p=0.70$ \\
\hline Algebra-based shift: $1.6 \%$ & $\cdots$ & $\cdots$ & $\ldots$ & $p=0.83$ \\
\hline Upper-level shift: $-2.8 \%$ & $\cdots$ & $\cdots$ & $\cdots$ & $\cdots$ \\
\hline
\end{tabular}

\section{E. Summary}

Our meta-analysis of the factors that may influence CLASS and MPEX overall shifts is consistent with claims in the literature about the influence of teaching methods, but class size and student population may also be important factors. Teaching method explains the largest amount of variation in the CLASS and MPEX shifts, followed by student population, and then class size, with all three factors being statistically significant. This is consistent with our observation that the plot of shifts in beliefs grouped by teaching method (Fig. 2) has the least variability within each category when compared to the plots of class size and student population (Figs. 3 and 4).

We did not find any significant interactions between teaching method, student population, and class size, though we observe in the data that courses with large positive shifts are those with an explicit focus on model building, small class sizes, and taught to elementary education and nonscience majors. The courses that tend to have negative shifts in beliefs are those taught with traditional or reformed teaching methods, large enrollments, calculus-based, and higher incoming beliefs. This lack of significant interactions between factors may be related to the large selection effects in this data set as a whole in terms of what kinds of classes researchers choose to study and report on and what factors they focus on.

We also found that teaching method is the strongest predictor of shifts on the CLASS and MPEX, even when pretest scores are taken into account. Student population and pretest score are marginally predictive of these shifts.

As mentioned above, the overall data set is deeply unbalanced, so conclusions should be interpreted with

\section{Pretest vs Shift Grouped by Teaching Method}

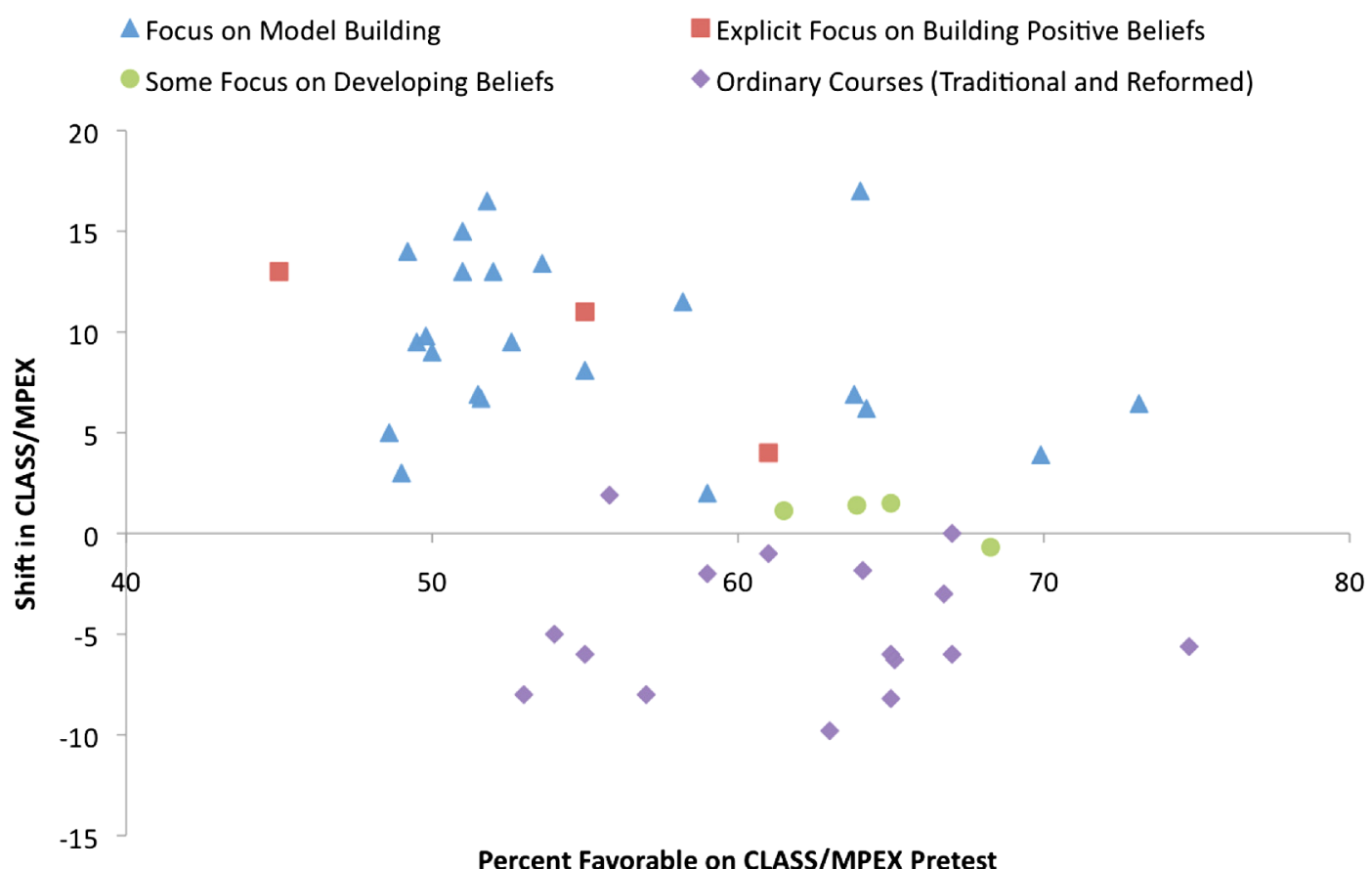

Percent Favorable on CLASS/MPEX Pretest

FIG. 5. Pretest percent expertlike scores versus shifts on CLASS and MPEX with data points grouped by teaching method. 


\section{Pretest vs Shift Grouped by Student Popuation}

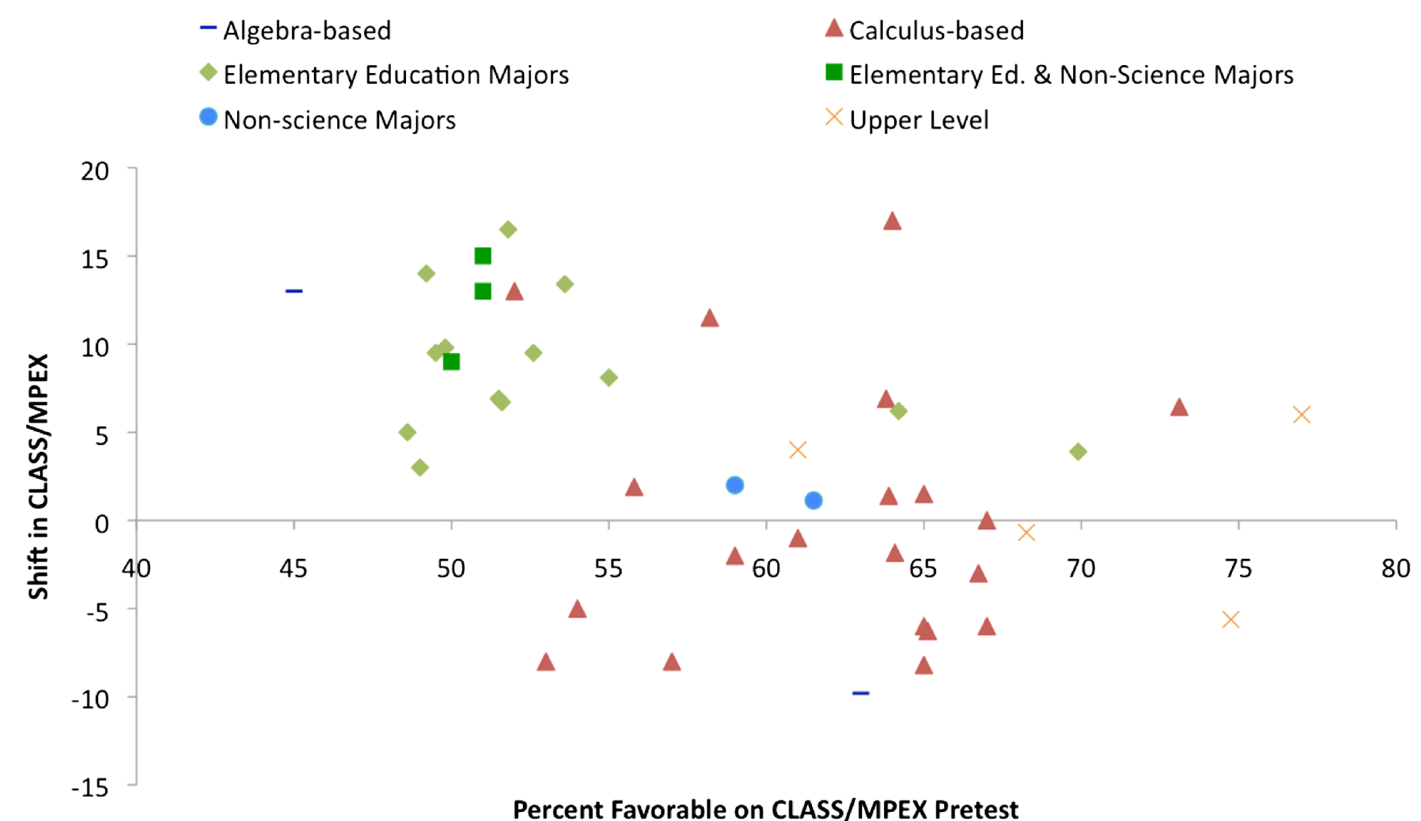

FIG. 6. Pretest percent expertlike scores versus shifts on CLASS and MPEX with data points grouped by student population.

caution. Researchers should fill in the gaps in this published record by focusing on factors beyond teaching method, so that we can determine how these other factors influence beliefs. For example, instructors should try to get large CLASS and MPEX gains in a large lecture class or an upper-division class using teaching methods that are successful in small introductory classes (though we acknowledge this will be difficult as many of these methods are designed for smaller courses). The CLASS and MPEX should be given to more classes for elementary education teachers that are taught using standard methods to determine whether the curricula with a focus on model building are leading to the large positive shifts, or if there is something unusual about this student population. The CLASS and MPEX should also be given in algebra-based courses, because there are only two published studies on this student population.

All of the data from the published record included in this meta-analysis are at the course level rather than the student level, giving us a coarse-grained view of students' beliefs. These data only indicate on average how teaching method, student population, class size, and pretest score influence shifts. Further, we have no information about within-class variation in shifts. If we instead used student-level data, we would be able to analyze the distribution in students' beliefs across the course and determine how the different factors investigated influenced this distribution. We could also determine how individual students' majors influence shifts instead of looking at the student population the course was intended for.

Our new Assessment Data Explorer, being developed as part of PhysPort [36], will address both of these concerns by collecting student-level assessment data. The assessment data explorer is discussed further in the "Future Directions" section below.

\section{WHEN AND HOW DO PHYSICS MAJORS DEVELOP EXPERTLIKE BELIEFS?}

It has been shown that most advanced physics students have expertlike beliefs about learning physics [37,38] and also that most ordinary introductory physics courses result in negative shifts in beliefs (unless the instructor does something special); so how do these physics majors develop the expertlike beliefs that allow them to succeed in their major and go on to be successful physicists? It could be that they develop these beliefs in their undergraduate education or perhaps those who choose to major in physics already had positive beliefs about physics, presumably developed during their K-12 education.

Below we describe the results of several studies that examine beliefs of physics majors over time. These studies find physics majors start their undergraduate education with higher CLASS scores than other majors. Even those intending to major in physics in high school have higher CLASS scores than those not intending to major in physics. This indicates that physics majors develop these expertlike views in their $\mathrm{K}-12$ education. These scores are relatively stable over the course of their undergraduate program when tracked longitudinally or looked at cross sectionally. There is a jump in scores from the end of the undergraduate program to the beginning of postgraduate work, though small numbers make this conclusion tentative. The details of these studies are described below. All of these results 
suggest that physics courses are selecting students with expertlike beliefs, rather than developing them.

\section{A. Cross-sectional studies of development of beliefs}

Cross-sectional studies of beliefs take snapshots of different students' beliefs in a given year, for example, collecting belief data from freshman, junior, sophomore, and senior physics majors at the same time in the same year and comparing them. These kinds of studies let us compare the beliefs of students at different points in their education and determine how their courses influence their beliefs over time. These kinds of data are limited by the fact that many factors in addition to year in school could influence students' beliefs; for example, differing entrance requirements, class culture, class sizes, or teaching experience of faculty and the effect of these different factors is not easily differentiated.

Two cross-sectional studies found that physics majors' expertlike belief scores are relatively consistent across years. Bates et al. [39] surveyed physics majors in years 1-4 of their undergraduate curriculum, high school students, and a group of post-docs and faculty in a given year. They found no significant differences in the percentage of expertlike responses across years 1-4 of the undergraduate curriculum with the exception of a drop in scores in year 3 . They believe this drop in year 3 data is anomalous. Bates et al. also compared scores of high school students intending to become physics majors and first year students intending to become physics majors and found no differences. They did find a statistically significant jump between year 4 students and postgraduates.

Gire, Jones, and Price [38] compared students' beliefs in years $1-3$ of the undergraduate curriculum in a given year and found no differences in scores by year. There were a small number of year $4(n=16)$ and graduate students $(n=7)$, so these are not included in their analysis, but the raw scores for year 4 and graduate students are higher than scores for years $1-3$. Neither study controlled for dropouts, so any differences in scores between students in different years could be due to students with less expertlike physics not continuing in the major. That is, there could be a selection effect and scores in later years could increase because only students with expertlike beliefs about physics continued in their physics education.

\section{B. Longitudinal studies of development of beliefs}

Longitudinal studies follow a cohort of students throughout their undergraduate physics program and compare their expertlike belief scores over time [38,40]. These studies allow us to draw stronger conclusions about how students' beliefs change over time than cross-sectional studies, but the data are more difficult to collect due to the longer timeframe and requirement to follow the same students. Two longitudinal studies of beliefs found that individual students' scores do not change over the course of their undergraduate program. Slaughter, Bates, and Galloway [40] followed a cohort of 35 students through their first three years of the physics program. The CLASS was given as a pre- and post-test the first year, and a post-test in years 2 and 3. They found no statistically significant differences between years. Similarly, Gire, Jones, and Price [38] found that most students' responses are stable over years 1-3 of the physics program, with $70 \%$ of students changing their answers by less than two questions (in this study, 51 physics majors responded to the CLASS more than once, but not all participants responded three times during years 1-3). These studies in tandem with the cross-sectional studies indicate that physics majors maintain their beliefs about learning physics over the course of the first three years. It is not their university courses that help them develop their beliefs; they already have them coming in.

\section{How does the development of beliefs of physics majors compare to other majors?}

Several studies have compared the beliefs of physics majors and other majors over time and they all conclude that students who major in physics enter the physics program with more expertlike views than those who don't major in physics and these views are developed in their K-12 education. Perkins and Gratny [41] collected pretest CLASS data and intended major for students in their first university physics class. They waited several years and identified those students who actually majored in physics. They compared those who intended to major in physics, actually majored in physics, and majored in something else. They found that percent expertlike belief scores of those who actually majored in physics $(78.3 \% \pm 1.4 \%)$ were significantly higher than those who intended to major in physics $(73.5 \% \pm 1.2 \%)$ and the overall population $(64.7 \% \pm 0.3 \%)$. Gire and Jones [38] found that CLASS scores for physics majors in years 1-3 were higher than those of first year engineering students. Bates et al. [39] found that CLASS scores of high school students intending to major in physics were similar to those of first year physics majors, but high school students not intending to major in physics scored lower than those intending to major in physics and first year physics majors.

\section{Conclusion}

The cross-sectional studies, longitudinal studies, and comparisons between physics majors and other majors all point to the same conclusion: students who major in physics enter their university education with more expertlike beliefs than other majors and these beliefs are relatively stable over the course of their undergraduate career. This suggests that our undergraduate programs are not helping physics students develop more expertlike views of physics; they are only selecting for students who have developed these beliefs elsewhere. Further, the finding that students develop their expertlike views in their $\mathrm{K}-12$ education 
raises the question, "what leads to the development of these expertlike beliefs?" These studies do not contain information about what kinds of physics instruction these students' had in high school, so we cannot determine if these expertlike beliefs were developed as a result of teaching methods. We do know that most high school courses have small enrollments, and that students in small classes have significantly (or nearly significantly) more expertlike beliefs in our data set of university students (see Sec. III A). While small class sizes may contribute to the development of expertlike beliefs in students' $\mathrm{K}-12$ education, this does not explain why high school students planning to major in physics had more expertlike beliefs than those not intending physics as a major.

\section{HOW DO STUDENTS' BELIEFS IMPACT THEIR LEARNING OF PHYSICS CONTENT AND VICE VERSA?}

Physics faculty often have multiple learning goals for their students, including learning conceptual and analytical physics content, thinking like physicists, and developing expertlike beliefs. To what extent are conceptual knowledge gains [such as those measured on the Force Concept Inventory (FCI) [6] and the Force and Motion Conceptual Evaluation (FMCE) [7], or similar tests] correlated with beliefs shifts on the CLASS or MPEX?

This question is difficult to answer because the data are mixed and unbalanced. Many studies report conceptual gains on various research-based assessments and varying percent expertlike shifts on the CLASS and MPEX. See Refs. [2,16-19] for studies that report conceptual gains on research-based assessments and negative shifts on the CLASS and MPEX. Studies that report conceptual gains on research-based assessments and no shifts on the CLASS and MPEX include Refs. [16,18,19,42]. There are also studies that report conceptual gains on research-based assessments and positive shifts on the CLASS and MPEX [13,23,24,26,28-30]. Table X summarizes studies that correlate conceptual gains or losses with beliefs shifts.

As with all correlational studies, a correlation between these measures does not imply a causal relationship. The published record includes correlations between different combinations of pre- and postbeliefs and pre-, post-, and gain in knowledge being calculated. These relationships can be suggestive of an important relationship between beliefs and conceptual knowledge, but without information on other mediating variables, we cannot make causal inferences.

\section{A. Correlations between pre- or postconceptual knowledge and beliefs}

A correlation between students' incoming beliefs and incoming conceptual knowledge tells us about how students' experiences prior to this course have influenced where they start. Only one study analyzes the connection between the FCI pretest scores and overall percent expertlike pretest score on the CLASS. It found a small but significant positive correlation between these measures [13]. This study suggests that students with more expertlike incoming beliefs also have more conceptual knowledge. Presumably students with higher incoming conceptual knowledge have previously taken a physics course. Most ordinary physics courses result in negative shifts in beliefs, so it is perplexing that students who have likely taken a previous course have higher incoming beliefs. However, this correlation could be explained by the selection effects discussed in the previous section.

Another way to determine how students' beliefs about learning physics and conceptual knowledge are related is to

TABLE X. Correlations between surveys of beliefs about learning physics and other measures of learning. Numbers in brackets indicate the confidence interval which is significant if zero is not in the interval.

\begin{tabular}{|c|c|c|c|}
\hline Measures correlated & University and teaching method & $N$ & $\begin{array}{l}\text { Correlation coefficient } \\
\text { and significance }\end{array}$ \\
\hline \multicolumn{4}{|l|}{ Incoming beliefs } \\
\hline FCI pretest and CLASS pretest & Ryerson University, modified Peer Instruction [13] & 155 & $0.294(p<0.05)^{\mathrm{a}}$ \\
\hline $\begin{array}{l}\text { FMCE gain (if pretest score } \\
<60 \text { ) and CLASS pretest }\end{array}$ & University of Colorado, reformed calc-based [16] & 256 & $0.21(p<0.001)^{\mathrm{a}}$ \\
\hline $\begin{array}{l}\text { FMCE gain and CLASS pretest } \\
\text { Outgoing beliefs }\end{array}$ & University of Colorado, reformed calc-based [43] & 337 & 0.20 \\
\hline FCI post-test and MPEX post-test & Michigan State University, traditional lecture [44] & 84 & $0.24[0.04 \rightarrow 0.42]^{\mathrm{a}}$ \\
\hline FCI post-test and CLASS post-test & Ryerson University, modified Peer Instruction [13] & 155 & $0.258(p<0.05)^{\mathrm{a}}$ \\
\hline FCI gain and MPEX post-test & $\begin{array}{l}\text { Loyola Marymount University, interactive } \\
\text { engagement [45] }\end{array}$ & 37 & $0.52[0.24 \rightarrow 0.72]^{\mathrm{a}}$ \\
\hline FCI gain and MPEX post-test & Michigan State University, traditional lecture [44] & 84 & $0.17[-0.05 \rightarrow 0.37]$ \\
\hline $\begin{array}{l}\text { FMCE gain (if pretest score <60) } \\
\text { and CLASS post-test }\end{array}$ & University of Colorado, reformed calc-based [16] & 256 & $0.26(p<0.001)^{\mathrm{a}}$ \\
\hline Final exam and MPEX post-test & Michigan State University, Traditional lecture [44] & 97 & 0.27 \\
\hline Course grade and MPEX post-test & & & Weak \\
\hline
\end{tabular}

\footnotetext{
${ }^{\mathrm{a}}$ Indicates a significant correlation.
} 
look at students' outgoing beliefs and conceptual knowledge. A correlation between students' outgoing beliefs and outgoing conceptual knowledge (post-test scores) tells us how the conceptual knowledge students ended the course with is related to their beliefs at the end of the course. Since this is a relationship between measures taken at the end of the course, it is likely that specifics of the course influence it. Two studies $[13,44]$ have calculated the correlation between CLASS or MPEX post-test percent expertlike scores and FCI or FMCE post-test scores (see Table X for more details). Both found a small positive significant correlation between these measures, indicating that the conceptual knowledge students leave the course with is positively related to their beliefs about learning physics at the end of the course. The causal inferences we can draw from this correlation are limited, because these data don't tell us if the students with greater conceptual knowledge and beliefs also entered the course this way and how the course influenced their beliefs and knowledge.

\section{B. Correlations between gains on conceptual surveys and beliefs}

To get closer to answering the question, "Do students' beliefs about learning physics influence what they actually learn?" we can examine the relationship between students' incoming beliefs and the conceptual knowledge gained from the course. This relationship suggests how students' initial beliefs about learning physics may influence what they actually learn. It is plausible that those who have more expertlike beliefs about learning physics learn it more effectively because they are applying strategies that actually work. For example, students who believe that learning physics is all about memorization are likely to attempt to memorize facts about physics instead of constructing their own understanding of the set of rich interrelated concepts.

There are two studies that correlate normalized gain on the FCI or FMCE and students' incoming beliefs. One study found a small statistically significant correlation [16] and the other found a small correlation but the significance was not tested [43]. Both of these studies were at the same university with calculus-based physics students. These studies suggest that students who start physics with more expertlike beliefs gain more conceptual knowledge. If this were true, it would imply that helping students develop expertlike beliefs about learning physics would contribute to their ability to learn physics concepts. But these studies alone are not enough to make any strong causal inferences about how initial beliefs influence learning.

We can also examine how students' beliefs at the end of the course (post-test beliefs) are related to their gain in conceptual knowledge over the semester. This would tell us how what they learned in the course is related to what they believe about learning physics at the end of their course, though, once again, there are many things that happened in the course that may have influenced each of these. Three studies have looked at this relationship. One found a statistically significant positive correlation of a moderate size between FCI gain and MPEX post-test percent expertlike score [45] and another study found a small nonsignificant correlation for the same measures [44]. A third study found a small significant correlation between FMCE gain and CLASS post-test [16]. Together, these studies indicate the correlation between normalized gains on these mechanics conceptual tests and the surveys of beliefs about physics are small but present.

Most studies of reformed-based teaching methods result in substantially higher conceptual gains than traditional teaching methods. However, reform-based courses often result in large negative shifts in beliefs. This implies that the correlation between learning gain and shift is in some cases negative, where strong conceptual understanding does not automatically result in improved beliefs about physics.

\section{Conclusion}

More work is needed before we can answer the question, "How are students' beliefs about physics related to their learning of physics?" Studies find a small significant correlation between students' incoming beliefs about learning physics and their conceptual gains in the course, but there are many other variables, specifically those describing who the students are and what the course is like, that should be examined before we draw conclusions about how incoming beliefs influence learning. This finding suggests that those who have more expertlike ideas about learning physics learn more physics. If this was true, it implies that even if all you care about is student learning, helping cultivate expertlike beliefs in your students could improve their ability to learn physics. However, studies that investigate these effects are limited and more work needs to be done. For example, the relationship between how students' conceptual knowledge changed from the beginning to the end of the course (gain) and their change in beliefs from beginning to the end of the course (shifts) has not been studied. This correlation would help us see how changes in conceptual knowledge are related to changes in beliefs.

Additionally, the link between beliefs shifts and conceptual gains should be studied in more depth. Studies need to consider other variables that may also be correlated to conceptual gains and initial beliefs, specifically variables describing who the students are, e.g., physics background, major, math background, and variables that describe what the course is like, e.g., type of instruction.

\section{CONCLUSION AND DISCUSSION}

Studies of beliefs about learning physics using the CLASS and MPEX indicate the teaching method is the most important factor that influences the shift in beliefs from pre- to post-test, but that class size and student population also explain significant portions of the variance in shifts (though less so than teaching method). This is 
consistent with claims in the literature about how teaching methods influence beliefs (see Table VI). We find that courses with an explicit focus on modeling or developing students' expertlike beliefs have significantly greater shifts in CLASS and MPEX scores than courses with some focus on developing expertlike beliefs or ordinary courses. We also find that small classes have significantly greater shifts than large classes. Further, courses for elementary education and nonscience majors have greater shifts than calculus-based and upper-level courses.

We did not find significant interactions between teaching method, class size, or student population when testing their influence on shifts, but this may be a result of the unbalanced nature of the published data set. In our data set, most studies on small classes use teaching methods that focus on model building and are taught to elementary education majors where most studies which focus on courses taught with traditional or reformed teaching methods are in large classes taught to calculus-based students.

We also tested the influence of pretest score (incoming beliefs about learning physics) on shift, taking into account teaching method and student population. We found that teaching method is the strongest predictor of shifts on the CLASS and MPEX, even when pretest scores are included in the analysis. Pretest score and student population were found to be marginally predictive of these shifts.

To better answer the question, "Are the improvements in beliefs reported in the literature supported by teaching interventions, small class sizes, student population, pretest scores, or some combination of these?", researchers should focus on factors beyond teaching method. For example, instructors should try to get large positive CLASS and MPEX shifts in large lecture classes or upper-division classes using teaching approaches that are successful in small introductory classes. The CLASS and MPEX should be given to more classes for elementary education teachers that are taught using standard methods to determine whether the curricula with a focus on modeling building are leading to the large positive shifts, or if there is something unusual about this student population. The CLASS and MPEX should also be given in algebra-based courses, as there are only two published studies on this student population. Further, student-level data should be collected and reported so that we can understand within-class variation in shifts.

These studies also present some concerning findings: for most of our large ordinary calculus-based courses, students' beliefs get worse over the course of the semester. We expect students would better understand the discipline of physics and how to learn physics after completing a physics course. Instead, their beliefs become less expertlike and students leave their course believing that physics is, for example, about memorizing facts, plugging numbers into equations, and not relevant to their life. Many faculty hope that as a result of their taking a physics class, students will come to appreciate physics as a coherent and logical method of understanding the world and to recognize that they can use reason and experimentation to learn about the world, although this is not the case in many of our large courses. Tremendous progress has been made over the last 30 years to help students develop strong conceptual understanding in these courses. More work needs to be done to figure out how to support students in improving their beliefs about learning physics in these learning environments.

The small, preservice teacher courses that focus on model building consistently result in positive shifts in beliefs. These curricula are structured so that students work in small groups to perform experiments and gather evidence in order to build models of the physical world. They also participate in small group and whole classroom discourse to understand, validate, and refine these models, mirroring the way scientists create new knowledge. Researchers should try to implement teaching environments similar to these in larger calculus-based courses and look at the effect on students' beliefs, though we acknowledge this will be difficult as these methods are designed for smaller courses.

Explicitly focusing on developing students' beliefs about learning physics can also lead to positive shifts. There are a wide variety of strategies to do this including using labs to help students view physics as refining and reconciling intuitive ideas [4], activities where students reflect on their learning process [4], explicit epistemological framing of the course [4], modified Peer Instruction with discussions of intuitive answers to questions [4], epistemologized tutorials emphasizing the reconciliation of intuitive thinking and formal scientific thinking [29], and focus on the development of scientific ideas throughout history [23]. Strategies such as these should also be studied with a wider variety of courses and student populations.

Physics majors' beliefs remain relatively unchanged over the course of the physics major and those who major in physics have more expertlike beliefs than other majors. This indicates that we are not helping physics students develop expertlike beliefs, but instead those who become physics majors already have these expertlike views about learning physics. This is concerning, as those who enter the university with less expertlike beliefs aren't majoring in physics because this choice may be less readily available to them and they are less inspired to do so. A stronger focus on developing expertlike beliefs in introductory courses might allow a wider variety of students the opportunity to major in physics, though this finding is suggestive but weak. Future studies looking at how individual students' beliefs develop in their $\mathrm{K}-12$ education, how these change in introductory classes, and the relationship between beliefs and choice of major would clarify this finding.

Students' beliefs about physics are weakly but significantly correlated with measures of their conceptual understanding. Students who have more expertlike incoming or outgoing beliefs also have greater gains on research-based assessments of conceptual understanding, such as the FCI 
and the FMCE. Specifically, there is a small correlation between students' incoming beliefs about physics and their normalized gain on these mechanics concept inventories. This suggests that students with more expertlike incoming beliefs gain more conceptual knowledge in their physics course. There are only two studies looking at this correlation, so the results are somewhat inconclusive. Further, there are many other important variables that could influence beliefs and conceptual understanding that have not been studied. We encourage researchers to further study the relationship between beliefs about learning physics and conceptual understanding and variables that may influence this relationship, such as physics and math background and details of the course, in order to better understand how each develops and provide clues for instructors on how to support this process.

\section{FUTURE DIRECTIONS}

Through this analysis of existing CLASS and MPEX data, we have identified several open questions about how students' shifts in beliefs relate to what happens in the classroom. To more definitively answer these questions, a larger data set that included individual student level data is needed. We are currently developing a national database of research-based assessment results (including the CLASS and MPEX) on PhysPort [36] (formerly the PER User's Guide). Here instructors can upload their student's deidentified assessment data in order to visualize and analyze their results in a variety of ways. A database of this kind will give the PER community access to the kind of data needed to answer open questions such as, "Are the improvements in beliefs reported in the literature supported by teaching interventions, small class sizes, student population, pretest scores or some combination of these?", "How strongly do beliefs depend on the population of students and their backgrounds?", and "Do expertlike beliefs support student learning of physics, is it the other way around, or are there other important variables that influence one or both that haven't yet been studied?" This database will be ready for use by verified physics instructors in the fall of 2015 .

\section{APPENDIX}

The CLASS and the MPEX are very similar tests with similar goals, intended populations, administrative instructions, and scoring. However, there are some differences. This appendix compares the details of both tests (See Table XI).

TABLE XI. Comparison of the CLASS and MPEX surveys.

\begin{tabular}{|c|c|c|}
\hline & MPEX & CLASS \\
\hline $\begin{array}{l}\text { Structure } \\
\text { of survey }\end{array}$ & $\begin{array}{l}34 \text { items } \\
20-30 \text { minutes to complete } \\
5 \text { point Likert scale (strongly agree, } \\
\text { agree, neutral, disagree, strongly disagree) }\end{array}$ & $\begin{array}{l}42 \text { items }^{\mathrm{a}} \\
8-10 \text { minutes to complete }^{-1}\end{array}$ \\
\hline $\begin{array}{l}\text { Focus } \\
\quad \text { of survey }\end{array}$ & Student beliefs about the physics course & Student beliefs about the discipline of physics \\
\hline $\begin{array}{l}\text { Typical } \\
\text { administration }\end{array}$ & \multicolumn{2}{|c|}{$\begin{array}{c}\text { Pre- and post-test (beginning and end of course) Either online or paper } \\
\text { and pencil In class or at home }\end{array}$} \\
\hline $\begin{array}{l}\text { Survey } \\
\text { development } \\
\text { process }\end{array}$ & $\begin{array}{l}\text { Tested over the course of four years at } \\
15 \text { universities with over } 1500 \text { students. } \\
\text { Items chosen through } \\
\text { literature review, discussion with faculty, } \\
\text { and the researchers' personal experiences. }\end{array}$ & $\begin{array}{l}\text { Used seven design principles }\left(\mathrm{see}^{\mathrm{b}}\right) \text { to } \\
\text { revise MPEX and VASS questions and } \\
\text { create new ones. Conducted interviews } \\
\text { with students and relied on the language and } \\
\text { ideas students used to revise and create } \\
\text { new questions. }\end{array}$ \\
\hline $\begin{array}{l}\text { Validation of } \\
\text { survey items }\end{array}$ & \multicolumn{2}{|c|}{ Student interviews where students were asked to explain why they chose each answer. } \\
\hline $\begin{array}{l}\text { Student } \\
\text { population } \\
\text { tested }\end{array}$ & Primarily calculus-based physics students & $\begin{array}{l}\text { Conceptual physics, algebra-based and } \\
\text { calculus-based physics students }\end{array}$ \\
\hline $\begin{array}{l}\text { Source of "expert" } \\
\text { or "favorable" } \\
\text { response }\end{array}$ & $\begin{array}{l}19 \text { physics faculty implementing Workshop } \\
\text { Physics. } 80 \% \text { agreement level reached } \\
\text { on all but three survey items. }\end{array}$ & $\begin{array}{l}16 \text { physics education researchers or physicists } \\
\text { involved in teaching. } 100 \% \text { agreement } \\
\text { level on all but four survey items. }\end{array}$ \\
\hline Scoring & $\begin{array}{l}\text { To find the percent of expertlike response for } \\
\text { each student, the number of "agree" and } \\
\text { "strongly agree" responses are added together } \\
\text { and divided by the total number of survey items. } \\
\text { A similar process followed to find the percent } \\
\text { of novicelike responses. }\end{array}$ & \\
\hline
\end{tabular}


TABLE XI. (Continued)

\begin{tabular}{|c|c|c|}
\hline & MPEX & CLASS \\
\hline Categories & $\begin{array}{l}\text { - Independence } \\
\text { - Coherence } \\
\text { - Concepts } \\
\text { - Reality link } \\
\text { - Math link } \\
\text { - Effort }\end{array}$ & $\begin{array}{l}\text { - Real-world connections } \\
\text { - Personal interest } \\
\text { - Sense-making or effort } \\
\text { - Conceptual connections } \\
\text { - Applied conceptual understanding } \\
\text { - Problem solving general } \\
\text { - Problem solving confidence } \\
\text { - Problem solving sophistication } \\
27 \text { items are in one of these categories, } 9 \\
\text { more are valid and reliable, } 8 \text { items are } \\
\text { not scored because there is no expert } \\
\text { response or the validity has not been established. }\end{array}$ \\
\hline $\begin{array}{l}\text { Category } \\
\text { creation }\end{array}$ & $\begin{array}{l}\text { Categories decided a priori by researchers-a } \\
\text { deliberate decision consistent with the researchers' } \\
\text { resources theoretical viewpoint in which students' } \\
\text { beliefs are viewed as local coherences, not stable } \\
\text { mental structures [46]. Statistical analyses found } \\
\text { that survey items in some categories are only } \\
\text { weakly correlated in actual student responses }{ }^{b} \text {. }\end{array}$ & $\begin{array}{l}\text { Categories created using reduced-basis factor } \\
\text { analysis, where raw statistical categories } \\
\text { and categories predetermined } \\
\text { by researchers were combined iteratively. } \\
\text { They ensured that the } \\
\text { questions in each category were correlated } \\
\text { in actual student responses. }\end{array}$ \\
\hline Limitations & $\begin{array}{l}\text { Measure self-1 } \\
\text { Several items contain two statements, which are } \\
\text { sometimes interpreted inconsistently by students. } \\
\text { It is unclear how students who have never taken } \\
\text { a physics course interpret the questions since } \\
\text { they are strongly grounded in the physics course. }\end{array}$ & $\begin{array}{l}\text { orted beliefs. } \\
\text { Test contains unscored items for which } \\
\text { validity has not been established. }\end{array}$ \\
\hline
\end{tabular}

"a The CLASS has more items than the MPEX (42 vs 33) but it takes less time for students to respond to them, presumably because the items on the CLASS are easier to parse.

'It has been found that students don't consistently interpret agree and strongly agree in the same way, so combining these results is appropriate [45].

[1] E. F. Redish, J. M. Saul, and R. N. Steinberg, Student expectations in introductory physics, Am. J. Phys. 66, 212 (1998).

[2] W. Adams, K. Perkins, N. Podolefsky, M. Dubson, N. Finkelstein, and C. Wieman, New instrument for measuring student beliefs about physics and learning physics: The colorado learning attitudes about science survey, Phys. Rev. ST Phys. Educ. Res. 2, 010101 (2006).

[3] I. Halloun, Views about science and physics achievement: The VASS story, AIP Conf. Proc. 399, 605 (1997).

[4] A. Elby, Helping physics students learn how to learn, Am. J. Phys. 69, S54 (2001).

[5] S. Chen, Development of an instrument to assess views on nature of science and attitudes toward teaching science, Sci. Educ. 90, 803 (2006).

[6] D. Hestenes, M. M. Wells, and G. Swackhamer, Force concept inventory, Phys. Teach. 30, 141 (1992).

[7] R. K. Thornton and D. R. Sokoloff, Assessing student learning of Newton's laws: The force and motion conceptual evaluation and the evaluation of active learning laboratory and lecture curricula, Am. J. Phys. 66, 338 (1998).

[8] S. Sharma, P. K. Ahluwalia, and S. K. Sharma, Students' epistemological beliefs, expectations, and learning physics: An international comparison, Phys. Rev. ST Phys. Educ. Res. 9, 010117 (2013).
[9] J. de la Garza and H. Alarcon, Assessing students' attitudes in a college physics course in Mexico, AIP Conf. Proc. 1289, 129 (2010).

[10] H. Alhadlaq, F. Alshaya, S. Alabdulkareem, K. K. Perkins, W. K. Adams, and C.E. Wieman, Measuring students' beliefs about physics in Saudi Arabia, AIP Conf. Proc. 1179, 69 (2009).

[11] L. Ding, A comparative study of middle school and high school students' views about physics and learning physics, AIP Conf. Proc. 1513, 118 (2013).

[12] J. Marx and K. Cummings, What factors really influence shifts in students' attitudes and expectations in an introductory physics course?, AIP Conf. Proc. 883, 101 (2007).

[13] M. Milner-Bolotin, T. Antimirova, A. Noack, and A. Petrov, Attitudes about science and conceptual physics learning in university introductory physics courses, Phys. Rev. ST Phys. Educ. Res. 7, 020107 (2011).

[14] Z. Hrepic, P. Adams, J. Zeller, N. Talbott, G. Taggart, and L. Young, Developing an inquiry-based physical science course for preservice elementary teachers, AIP Conf. Proc. 818, 121 (2006).

[15] C. H. Crouch, P. Wisittanawat, and K. A. Renninger, in Initial Interest, Goals, and Changes in CLASS Scores in Introductory Physics for Life Sciences, 2013 PERC Proceedings, edited by P. V. Engelhardt, A. D. Churukian, and 
D. L. Jones (American Association of Physics Teachers, Portland, OR, 2013), pp. 105-108.

[16] K. K. Perkins, W. K. Adams, S. J. Pollock, N. D. Finkelstein, and C. E. Wieman, Correlating student beliefs with student learning using the colorado learning attitudes about science survey, AIP Conf. Proc. 790, 61 (2005).

[17] L. Kost, S. Pollock, and N. Finkelstein, Characterizing the gender gap in introductory physics, Phys. Rev. ST Phys. Educ. Res. 5, 010101 (2009).

[18] P. M. Miller, J. S. Carver, A. Shinde, B. Ratcliff, and A. N. Murphy, Initial replication results of learning assistants in university physics, AIP Conf. Proc. 1513, 30 (2013).

[19] S. B. McKagan, K. K. Perkins, and C. E. Wieman, Reforming a large lecture modern physics course for engineering majors using a PER-based design, AIP Conf. Proc. 883, 34 (2007).

[20] L. E. Kost-Smith, S. J. Pollock, and N. D. Finkelstein, Gender disparities in second-semester college physics: The incremental effects of a "smog of bias", Phys. Rev. ST Phys. Educ. Res. 6, 020112 (2010).

[21] B. A. Lindsey, L. Hsu, H. Sadaghiani, J. W. Taylor, and K. Cummings, Positive attitudinal shifts with the physics by inquiry curriculum across multiple implementations, Phys. Rev. ST Phys. Educ. Res. 8,010102 (2012).

[22] V. Otero and K. Gray, Attitudinal gains across multiple universities using the physics and everyday thinking curriculum, Phys. Rev. ST Phys. Educ. Res. 4, 020104 (2008).

[23] S. Garcia, A. Hankins, and H. Sadaghiani, The impact of the history of physics on student attitude and conceptual understanding of physics, AIP Conf. Proc. 1289, 141 (2010).

[24] F. Goldberg, E. Price, D. Harlow, S. Robinson, R. Kruse, and M. McKean, Development and evaluation of largeenrollment, active-learning physical science curriculum, AIP Conf. Proc. 1289, 153 (2010).

[25] V. Otero, S. Pollock, and N. Finkelstein, A physics department's role in preparing physics teachers: The colorado learning assistant model, Am. J. Phys. 78, 1218 (2010).

[26] E. Brewe, L. Kramer, and G. O'Brien, Modeling instruction: Positive attitudinal shifts in introductory physics measured with CLASS, Phys. Rev. ST Phys. Educ. Res. 5, 013102 (2009).

[27] E. Brewe, A. Traxler, J. de la Garza, and L. H. Kramer, Extending positive CLASS results across multiple instructors and multiple classes of modeling instruction, Phys. Rev. ST Phys. Educ. Res. 9, 020116 (2013).

[28] A. Pawl, A. Barrantes, and D. E. Pritchard, Modeling applied to problem solving, AIP Conf. Proc. 1179, 51 (2009).
[29] E. F. Redish and D. Hammer, Reinventing college physics for biologists: Explicating an epistemological curriculum, Am. J. Phys. 77, 629 (2009).

[30] C. De Leone, R. Marion, and C. Ishikawa, Adaptation and implementation of a radically reformed introductory physics course for biological science majors: Assessing success and prospects for future implementation, AIP Conf. Proc. 883, 113 (2007).

[31] D. B. Harlow, L. H. Swanson, H. A. Dwyer, and J. A. Bianchini, Learning pedagogy in physics, AIP Conf. Proc. 1289, 161 (2010).

[32] P. B. Kohl and H. V. Kuo, Introductory physics gender gaps: Pre- and post-studio transition, AIP Conf. Proc. 1179, 173 (2009).

[33] M. Krzywinski and N. Altman, Points of significance: Nonparametric tests, Nat. Methods 11, 467 (2014).

[34] L. C. McDermott (John Wiley \& Sons, New York, NY, 1996).

[35] http://petproject.sdsu.edu, (n.d.).

[36] www.physport.org, (n.d.).

[37] K. K. Perkins, M. M. Gratny, W. K. Adams, N. D. Finkelstein, and C. E. Wieman, Towards characterizing the relationship between students' interest in and their beliefs about physics, AIP Conf. Proc. 818, 137 (2006).

[38] E. Gire, B. Jones, and E. Price, Characterizing the epistemological development of physics majors, Phys. Rev. ST Phys. Educ. Res. 5, 010103 (2009).

[39] S. P. Bates, R. K. Galloway, C. Loptson, and K. A. Slaughter, How attitudes and beliefs about physics change from high school to faculty, Phys. Rev. ST Phys. Educ. Res. 7, 020114 (2011).

[40] K. A. Slaughter, S. P. Bates, and R. K. Galloway, A longitudinal study of the development of attitudes and beliefs towards physics, AIP Conf. Proc. 1413, 359 (2012).

[41] K. K. Perkins and M. Gratny, Who becomes a physics major? a long-term longitudinal study examining the roles of pre-college beliefs about physics and learning physics, interest, and academic achievement, AIP Conf. Proc. 1289, 253 (2010).

[42] P. B. Kohl and H. Vincent Kuo, Chronicling a successful secondary implementation of studio physics, Am. J. Phys. 80, 832 (2012).

[43] S. J. Pollock, No single cause: Learning gains, student attitudes, and the impacts of multiple effective reforms, AIP Conf. Proc. 790, 137 (2005).

[44] G. Kortemeyer, Correlations between student discussion behavior, attitudes, and learning, Phys. Rev. ST Phys. Educ. Res. 3, 010101 (2007).

[45] V. P. Coletta and J. A. Phillips, AIP Conf. Proc. 1289, 13 (2010). 